\author{
تعيين شماره منحنى از رويدادهاى بارش و رواناب و تغييرات آن با مؤلفهاى \\ بارش در يك حوضه آبخيز جنخلى \\ رئوف مصطفىزاده*، شهناز ميرزايى و بريا نديرى'

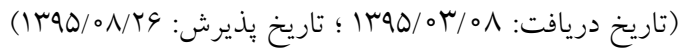

وازههاى كليدى: شماره منحنى، روش SCS-CN، خصوصيات رگبار، ضريب رواناب، مدل نمودار سه متغيره، حوضه آبخيز جعفر آباد

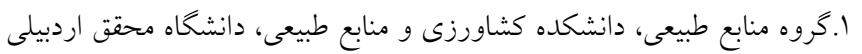

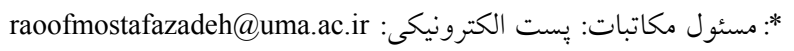


استفاده از آنها در تعيين شـماره منحنسى بـراى منــاطق مختلـف

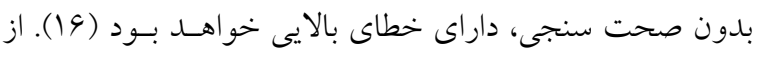

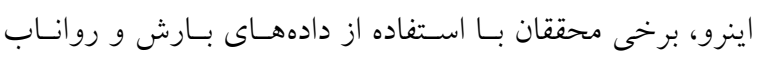

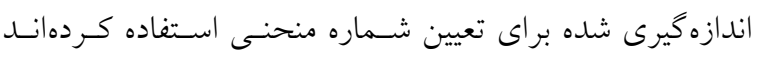

از جمله مطالعات انجام شده در زمينه تعيين مقــادير شـماره

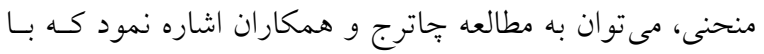

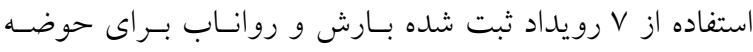
يايون در هند مقادير شماره منحنى را محاسبه كرده و بيان كردند كه مقادير شماره منحنى محاسبه شده در كاهش خططساى شـماره

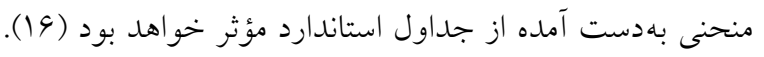
تدلا و همكاران در بررسى تأثير تغييرات فصلى بــرووى شـماره

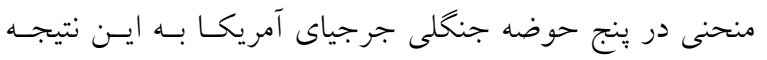
رسيدند كه مقدار شماره منحنى در فصـل رشــ كمتــ از فصـل

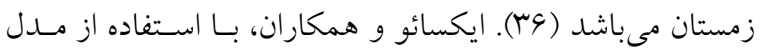

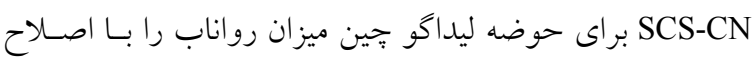

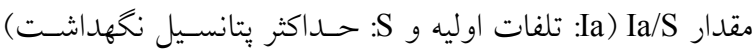

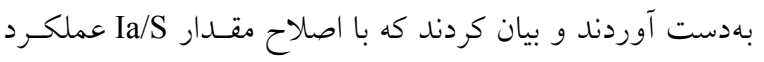

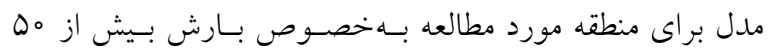
ميلى متر بهبود يافته است (1) (Y). سوليس و والينتز مقادير شـماره منحنى را در دو سيستم ناهمخن در منطقه ليكورم ايالات متحده آمريكا براساس دادههاى بارش و رو رواناب مداسبه كـرده و و بيـان

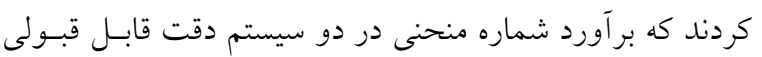
داشته است (WD). بناشيك و همكاران، با هــف تعيسين مقــادير شماره منحنى و بررسى كارايى روش SCS-CN در مناطق فاقــ

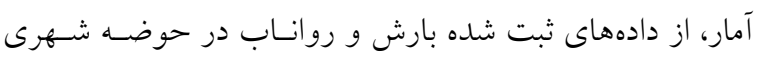

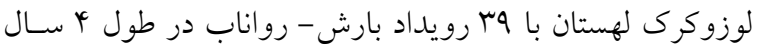

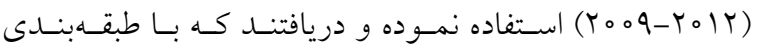

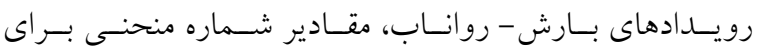

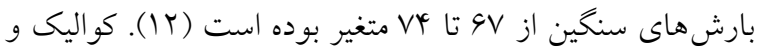

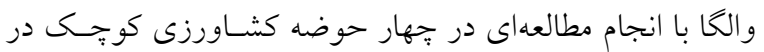

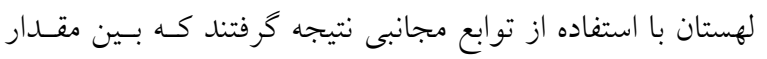

رواناب ناشى از بـارش در ايجـاد سـيلاب، فرسـايش و انتقـال

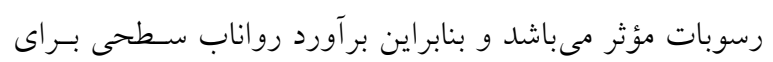

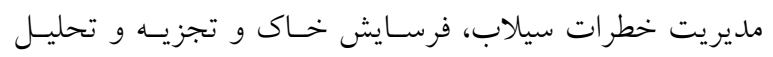

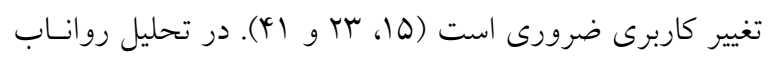

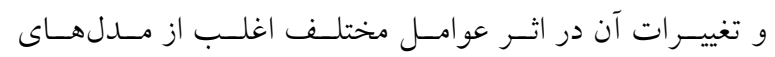

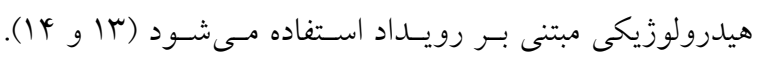

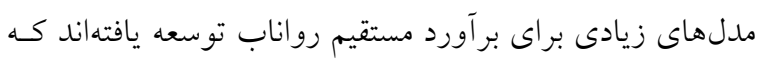

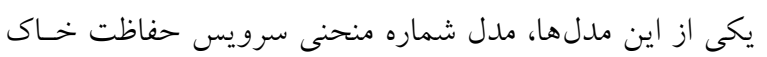

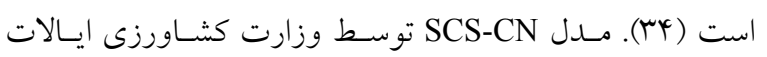
متحده توسعه يافته و يكى از مدلهاى ساده و تجربى است كس لهـ

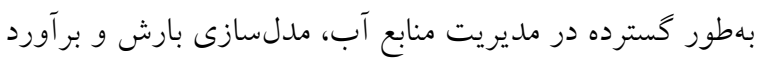

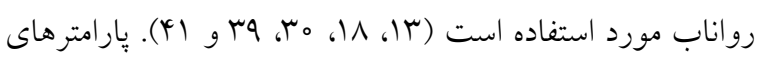

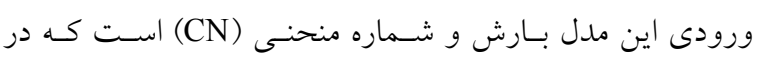

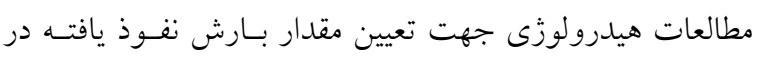

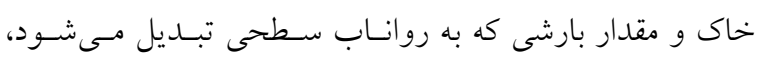

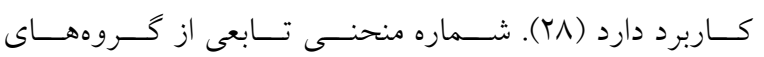

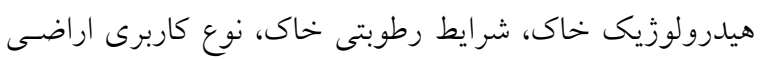

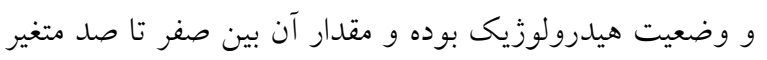

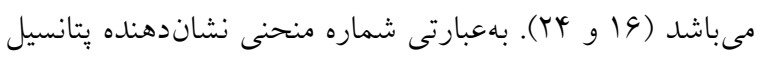

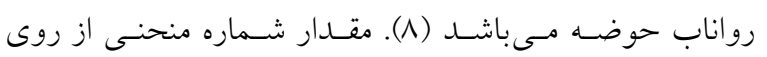

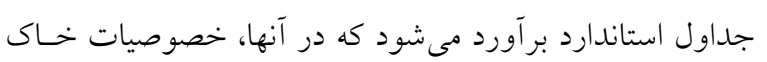

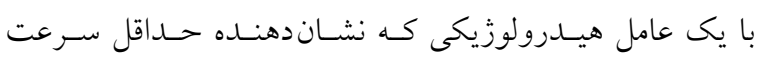

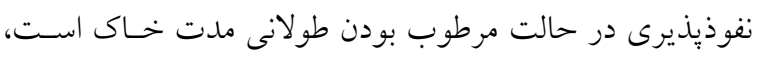
بيان مى شود. بر اين اساس سازمان حفاظت خاك آمريكـا تمـام

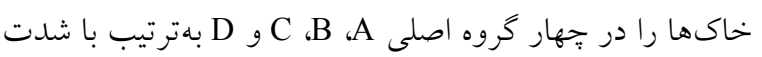
نفوذيذيرى بالا، متوسط، كم و خيلى كم تقسيم مى كند. همجنين

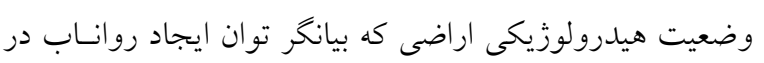

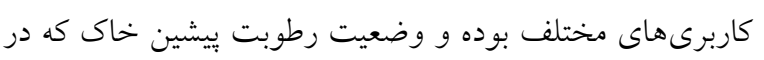

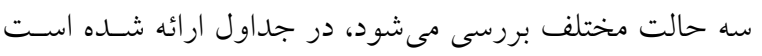

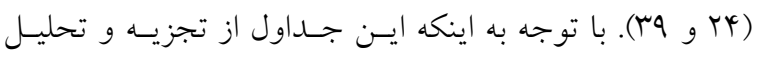

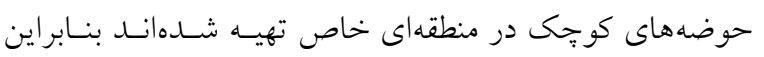


مى دهد. هدف از ئزوهش حاضر محاسبه مقدار شـماره منحنسى رويدادهاى ثبت شـده در طـول فصـول مختلـف بــا اسـتفاده از دادهــاى بـارش و روانـاب و مسـل SCS-CN اسـت. در ايسن

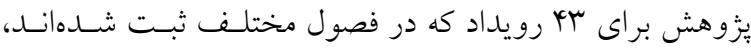

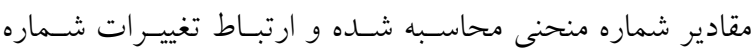
منحنى و مؤلفههاى بارش با استفاده از نمو دارهـاى سـه متغيـره مورد تجزيه و تحليل قرار كرفته است.

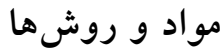

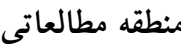
حوضه آبخيز جعفر آباد در محدوده جغرافيايى

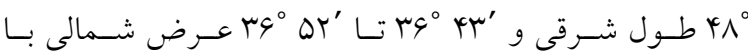
مساحت تقريبى ه 11 كيلومتر مربع در كQ كيلومترى جنوبشرق

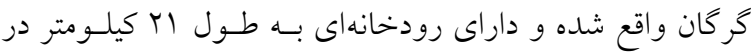

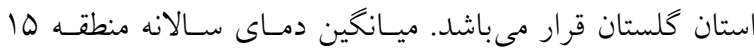
درجه سانتى گراد و متوسط بارش سالانه آن ه9 ميلى متر است. بخش قابل توجهى از اين حوضه را مناطق كوهستانى بوشيده از

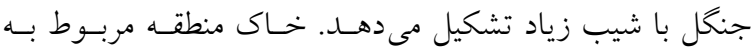
كروههاى هيدرولوزيك B و C بوده و زمينشناسى آن نيز بيشتر

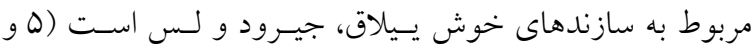

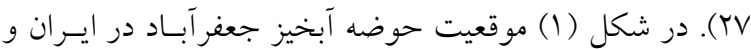
حوضه گر كانرود استان گلستان نشان داده شده است.

\section{روش تحقيق}

در اكثر مطالعـات بــرآورد روانـاب در شـــايط كشـور از روش شماره منحنى استفاده مى گردد. با وجود اينكه در اكثر حوضههـا

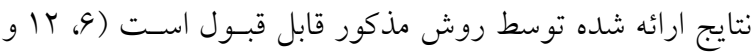

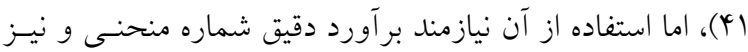
واسنجى مقدار تلفات اوليه براساس مقدار ضريب تجربى است. در يزوهش حاضر مقادير شماره منحنى بهصـورت معكسوس از

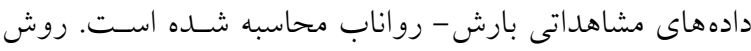

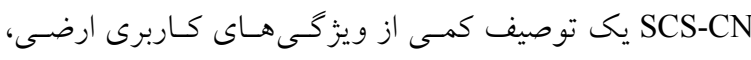

شماره منحنى مشاهداتى با مقدار بارش ارتباط قوى وجـود دارد

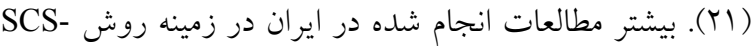
شامل برآورد رواناب مستقيم از دادههاى بـارش و ارزيسابى CN

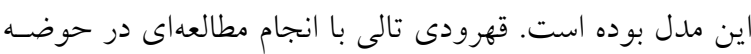

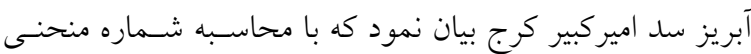

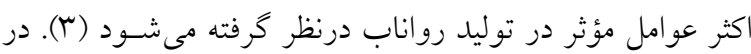

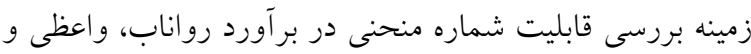

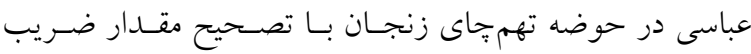

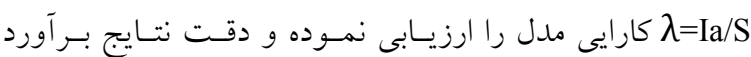

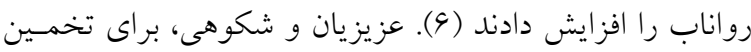

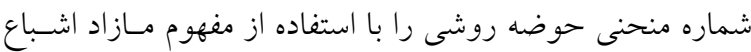

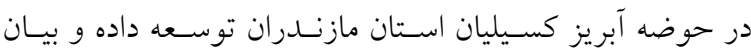
كردند كه ايـن روش از دقـت كـافى برخـوردار مسىباشـــ (Y).

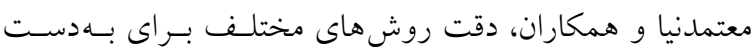

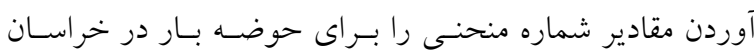

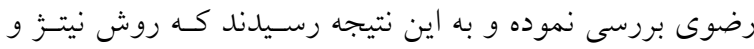

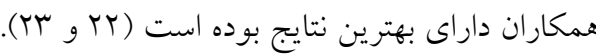
با توجه به اينكه شـماره منحنسى تـابعى از شـرايط خـاك و يوشش مىباشد، لذا مقادير آن در فصلهاى مختلف متغير بـوده

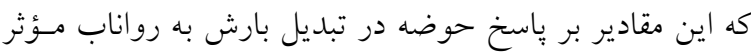

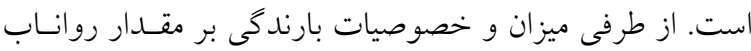
حاصل از روش شماره منحنى مؤثر است. در اين راستا، استفاده

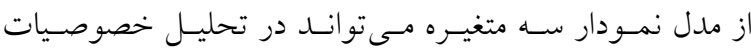

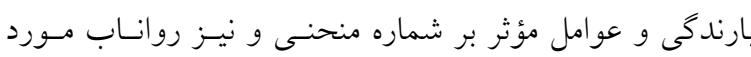

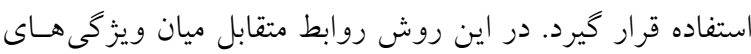
بارش و رواناب بر تخمين شماره منحنسى مـورد ارزيسابى قـرار

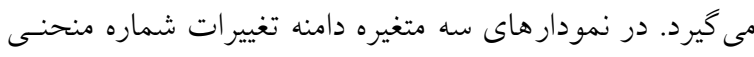

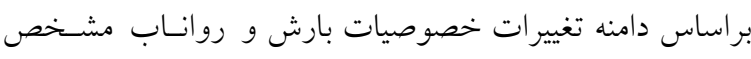

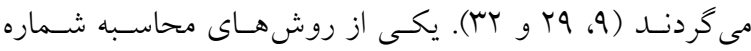
منحنى استفاده از دادههاى ثبت شده بارش و روانـاب بـهـعنـوان ورودىى و باسخ حوضه است و مدل SCS-CN بر بايه دادههـاى

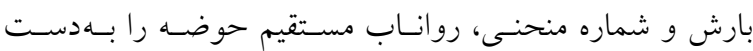




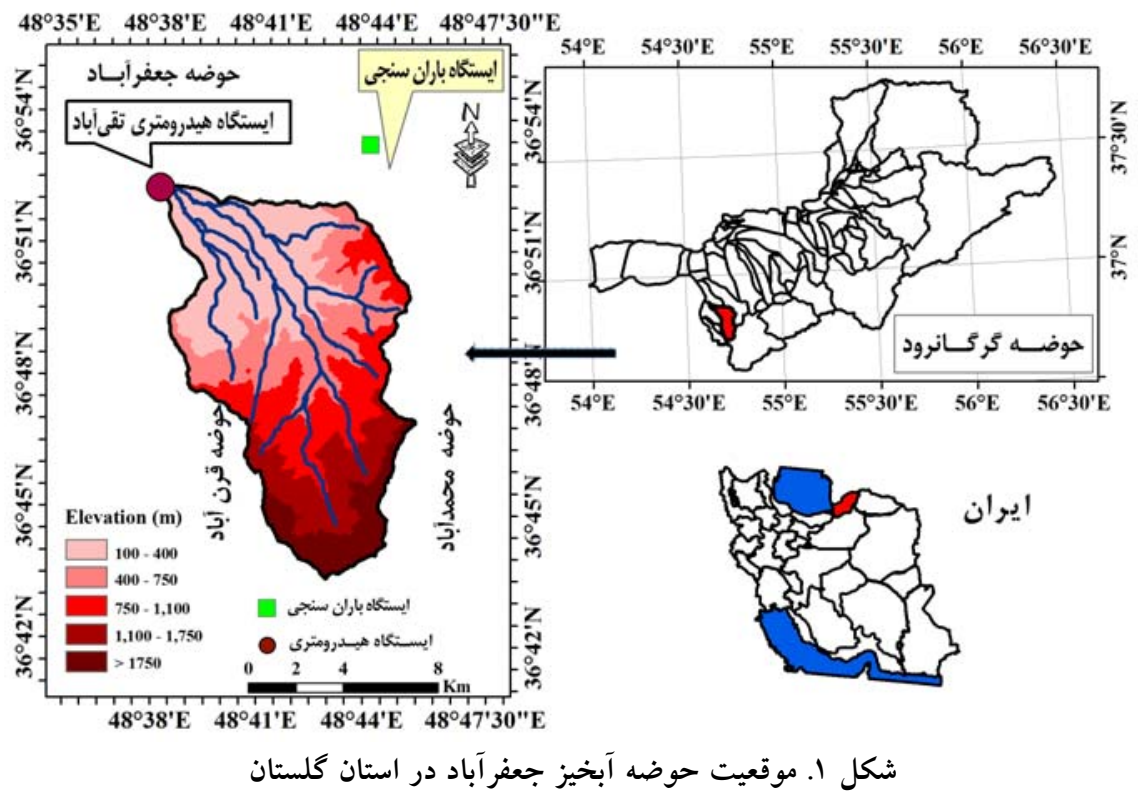

منطقه و بارش متفاوت بوده و نيازمند تصحيح مسىباشــ (19 و و

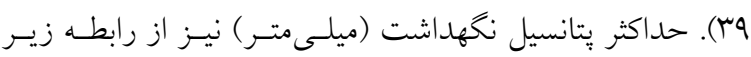

بر آورد شده است (19). (1).

$S=\frac{r \Delta Y \circ \circ}{C N}-r \Delta Y$

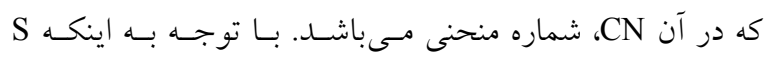

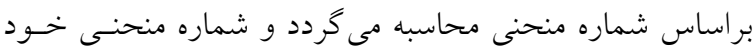

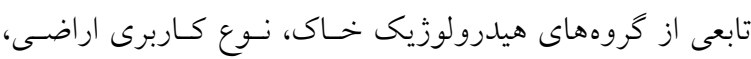

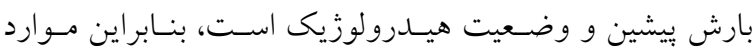

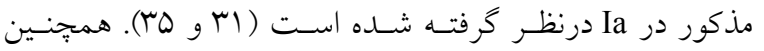
مقادير شماره منحنسى براسـاس جـــولهــاى اسـتاندارد كـه در شرايط مختلف و براى انواع كـاربرىهـاى اراضسى ارائسه شـــه

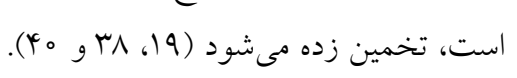

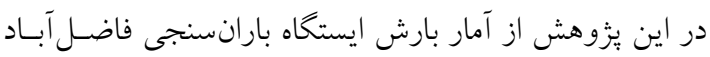

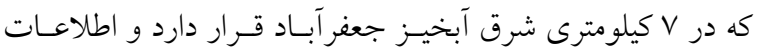

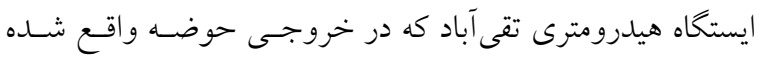

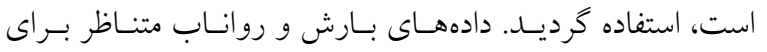
حوضه مورد مطالعه براساس طول دوره آمارى مشـترى 19 سـاله

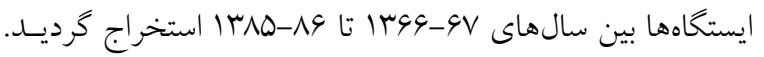

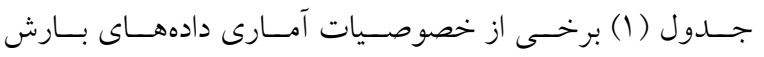

يوشش و خاك حوضـهـ آبخيـز اسـت و بــر بـيلان آب استوار

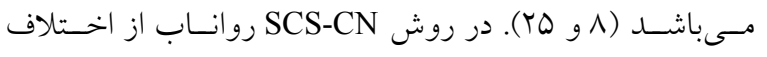

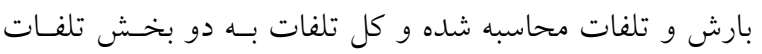

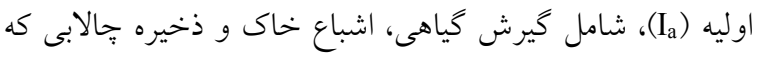

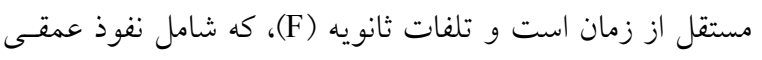

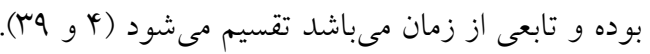
$\mathrm{Q}=\mathrm{P}-(\mathrm{Ia}+\mathrm{F})$ در اين رابطه Q، ارتفاع رواناب (ميلىمتـر) و P ارتفـاع بـارش

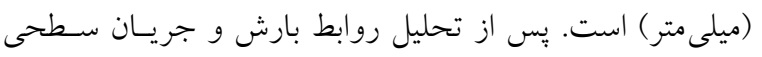

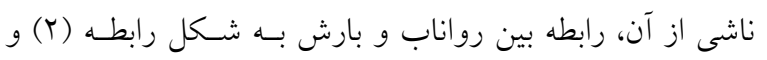

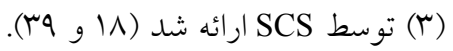
$\mathrm{Q}=\frac{\left(\mathrm{P}-\mathrm{I}_{\mathrm{a}}\right)^{r}}{\mathrm{P}-\mathrm{I}_{\mathrm{a}}+\mathrm{S}}$

$\mathrm{Q}=\frac{(\mathrm{P}-\circ / r \mathrm{~S})^{r}}{\mathrm{P}+\circ / \wedge \mathrm{S}}$

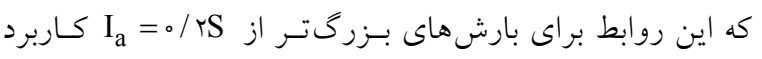

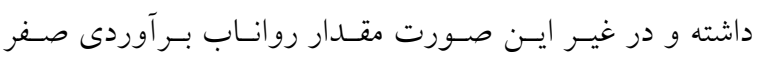

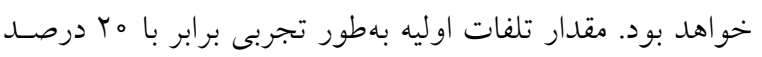

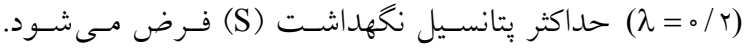
مقادير ضريب ג بين صفر - r/ه مى باشد كسه براسـاس شـرايط 
تعيين شماره منحنى از رويدادهاى بارش و رواناب و تغييرات آن با مؤلفههاى ...

جدول ا. خصوصيات آمارى دادههاى بارش و رواناب مشاهداتى در فصول مختلف سال

\begin{tabular}{|c|c|c|c|c|c|}
\hline 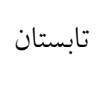 & 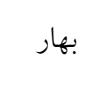 & ز إمستان & 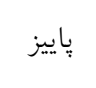 & & 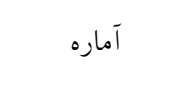 \\
\hline$V / I F$ & $V / \wedge 9$ & $10 / 1 \circ$ & $9 / 0 \circ$ & مدت زمان بارش (ساعت) & \multirow{6}{*}{ ميانخين } \\
\hline$I V / T V$ & $r I / \circ V$ & $|V / D|$ & $r V / Q_{0}$ & بارش كل (ميلىمتر) & \\
\hline $10 / \mathbb{F V}$ & $19 / 91$ & $Y / Q \circ$ & $V / 44$ & دبى اوج (مترمكعب بر ثانيه) & \\
\hline $1 / \mathrm{V}$ & $\varphi / \Delta r$ & $1 / 49$ & I/NT & دبى ميانخين (مترمكعب بر ثانيه) & \\
\hline TY/OH & $4 q / 4 q$ & $r Y / A M$ & $19 / 01$ & ضريب رواناب (درصد) & \\
\hline$r / V \circ$ & $r / \wedge 9$ & $r / 01$ & $Y / V 4$ & شدت بارش (ميلىمتر بر ساعت) & \\
\hline$Y / I r$ & $r / 91$ & $V / T Y$ & $r / 99$ & مدت زمان بارش (ساعت) & \multirow{6}{*}{ انحر اف معيار } \\
\hline $1 \% / 99$ & $11 / 91$ & $11 / 0 \mu$ & IN/VG & بارش كل (ميلىمتر) & \\
\hline $1 \mathrm{~V} / 9 \mathrm{~V}$ & $r M /$ TS & $r / \wedge \Delta$ & $4 / \Lambda 1$ & دبى اوج (مترمكعب بر ثانيه) & \\
\hline$r / 41$ & r/N &.$/ 99$ & $0 / 99$ & دبى ميانخين (مترمكعب بر ثانيه) & \\
\hline$r r / 99$ & $r Q / N$ & IV/AV & $1 r / \circ r$ & ضريب رواناب (درصد) & \\
\hline $1 / 09$ & $1 / \wedge 9$ &.$/ 91$ & r/DQ & شدت بارش (ميلىمتر بر ساعت) & \\
\hline $19 / 00$ & $r \circ \% \circ$ & $r \Lambda / \circ \circ$ & $1 Y / 00$ & مدت زمان بارش (ساعت) & \multirow{6}{*}{ حداكثر } \\
\hline$\varphi \varphi / V_{0}$ & $\varphi Q / \Lambda \circ$ & $\varphi \Delta / \Gamma_{0}$ & $9 r / 00$ & بارش كل (ميلىمتر) & \\
\hline$\Delta r / \circ \circ$ & $91 / \circ 0$ & $11 / V_{0}$ & $19 / 0 \circ$ & دبى اوج (مترمكعب بر ثانيه) & \\
\hline$V / T \wedge$ & $1 \% / 0 r$ & r/Ar & $\mathrm{r} / \mathrm{V}$ & دبى ميانخين (مترمكعب بر ثانيه) & \\
\hline $100 \%$ & $10 \wedge / 9 Y$ & $9 \circ / V 9$ & $0 Y / 99$ & ضريب رواناب (درصد) & \\
\hline $9 / Y_{0}$ & 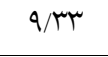 & $r / \varphi_{0}$ & $I T / T Q$ & شدت بارش (ميلىمتر بر ساعت) & \\
\hline$r / \circ \circ$ & Y/O० & $r / \circ \circ$ & $\varphi / 0 \circ$ & مدت زمان بارش (ساعت) & \multirow{6}{*}{ حداقل } \\
\hline$V / Y_{0}$ & $0 / 0 \circ$ & $9 / 4 \circ$ & $\Delta / V 。$ & بارش كل (ميلى متر) & \\
\hline $0 / Y_{1}$ & $r / 90$ & $1 / \mu_{1}$ & $r / 90$ & دبى اوج (مترمكعب بر ثانيه) & \\
\hline$\circ / 0 r$ & $1 / 09$ & $0 / 44$ & o/Ar & دبى ميانخين (مترمكعب بر ثانيه) & \\
\hline$\circ / \mu \wedge$ & $V / 90$ & $r / 10$ & $9 / 19$ & ضريب رواناب (درصد) & \\
\hline $1 / Y_{0}$ & $\circ / 9 \circ$ & $\circ / \mathrm{VA}$ & $1 / 4$ & شدت بارش (ميلىمتر بر ساعت) & \\
\hline$\circ / 0 \wedge$ & $\circ / 0 \circ$ & $0 / 9 \mathrm{~V}$ & $0 / 49$ & مدت زمان بارش (ساعت) & \multirow{6}{*}{ ضريب تغييرات } \\
\hline$\circ / N$ & $\circ / \mathrm{QV}$ & $0 / 94$ & $0 / 9 \mathrm{~V}$ & بارش كل (ميلىمتر) & \\
\hline $1 / 99$ & $1 / 19$ & $0 / 94$ & $0 / 94$ & دبى اوج (مترمكعب بر ثانيه) & \\
\hline $1 / 44$ & $\circ / \wedge \Delta$ & $0 / 94$ & $\circ / 0 \mathrm{~V}$ & دبى ميانخين (مترمكعب بر ثانيه) & \\
\hline $1 / 49$ & $\circ / \Delta \Delta$ & $\circ / \mathrm{VA}$ & $0 / 99$ & ضريب رواناب (درصد) & \\
\hline$\circ / 0 \wedge$ & $0 / 94$ & $\circ / 40$ & $\circ / V Q$ & شدت بارش (ميلىمتر بر ساعت) & \\
\hline
\end{tabular}


يزووهش، ارتباط ميان شماره منحنسى محاسباتى و خصوصسيات مربوط به بارش شامل مدت زمان بارش كـل مل (سـاعت)، مقــدار

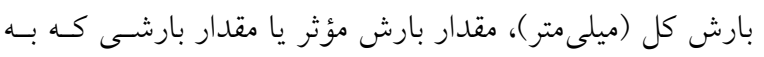

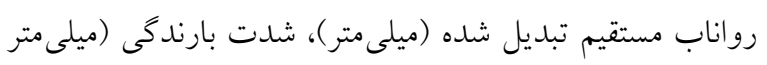

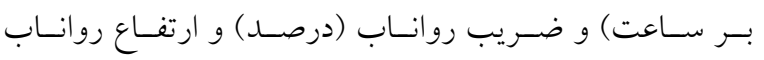

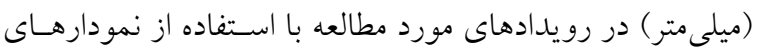

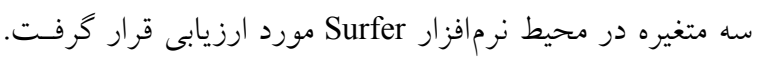

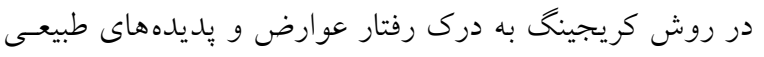

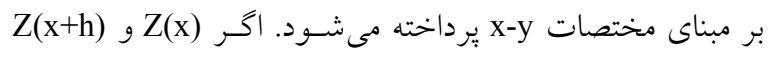

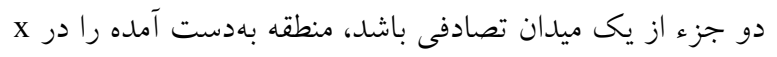

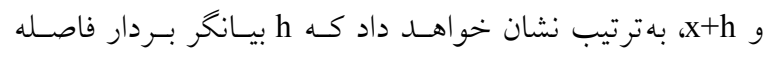

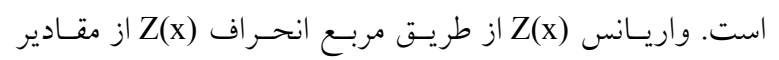
ميانخين m(x) براساس رابطه (ه) محاسبه گرديد: $\operatorname{Var}[Z(x)]=E[Z(x)-m(x)]^{r}$ كه E نمايش دهنده مقادير عملكر مورد انتظـار اسـت همجنـين

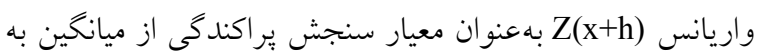

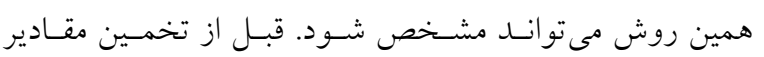

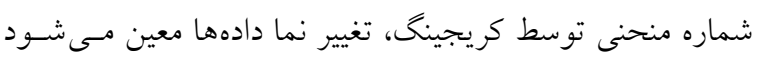

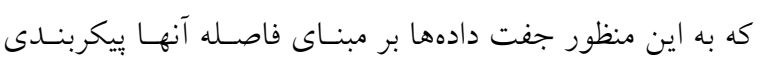

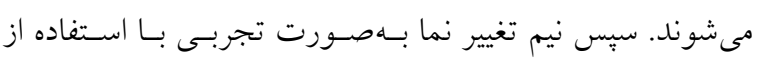

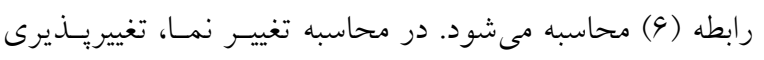

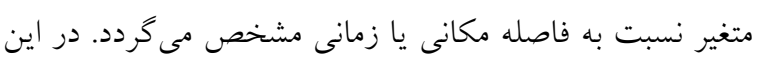

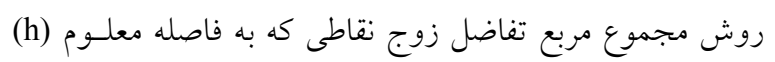

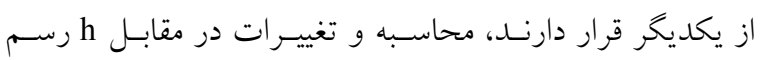

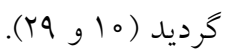

$\gamma(|\mathrm{h}|)=\frac{1}{r \mathrm{~N}(|\mathrm{~h}|)} \sum_{\mathrm{i}=1}^{\mathrm{N}(|\mathrm{h}|)}\left[\mathrm{Z}\left(\mathrm{x}_{\mathrm{i}}+\mathrm{h}^{\prime}\right)-\mathrm{Z}\left(\mathrm{x}_{\mathrm{i}}\right)\right]^{\mathrm{r}}$

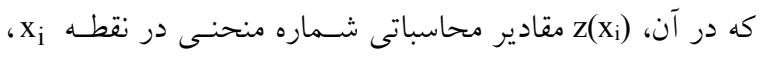

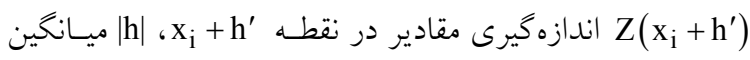

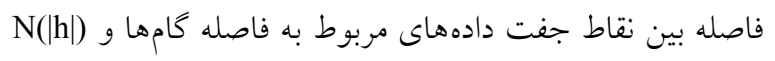

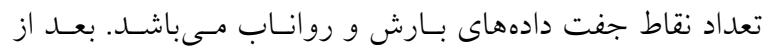

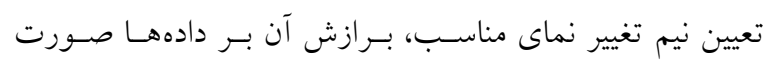

و رواناب مشاهداتى به تفكيك فصـول مختلـف سـال را نشـان مى مهد. در ادامه براى به رويداد متناظر بـارش و روانـاب براسـاس

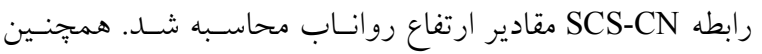

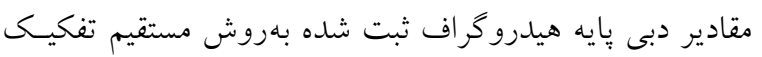

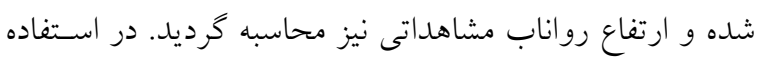
از روش تفكيك دبى بايه بهروش مستقيم، واكنش سريع آبخيـز

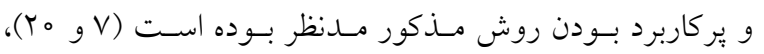

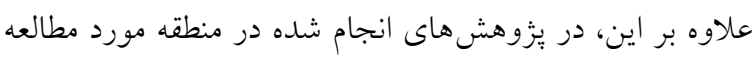

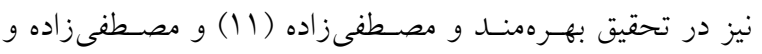

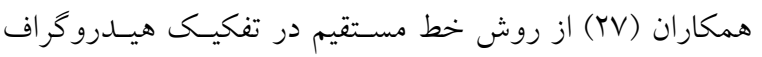

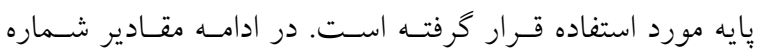

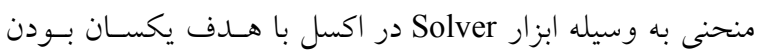

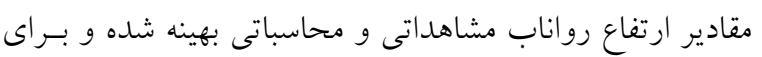

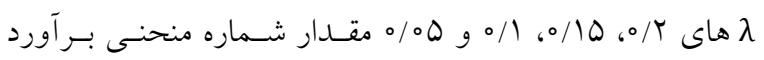

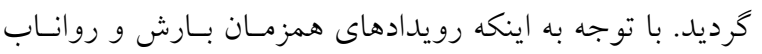
مربوط به فصول مختلف سـال بودنـــ بنـابراين تفـاوت مقـادير

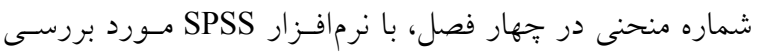

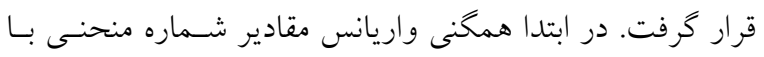

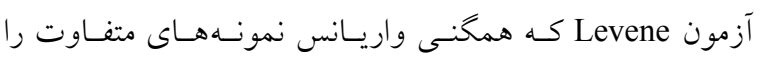

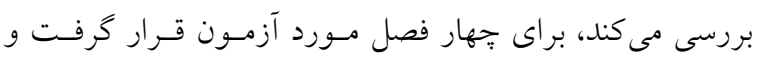

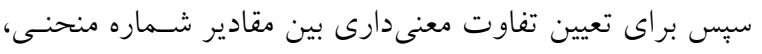

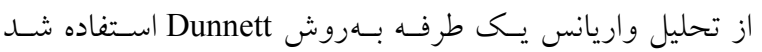

در مرحلهى بعل به منظور تحليل ارتباط تغييرات شماره منحنسى

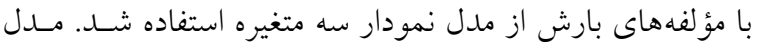

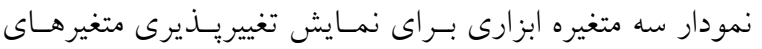
مؤثر بر يكى متغير وابسته در فضاى سه بعـدى اسـت (9). تهيــه

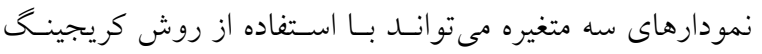
صورت گيرد، كه در آن با استفاده از دو متغيــر مسـتقل، نمـودار

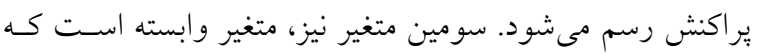

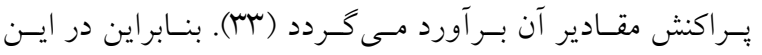


واريانس يكى طرفه بررسى شد كـه نتـايج در شـكل (Y) ارائسه شده است.

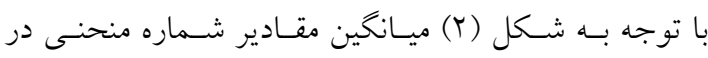

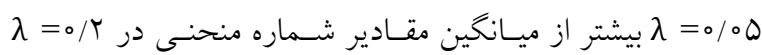

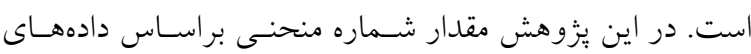

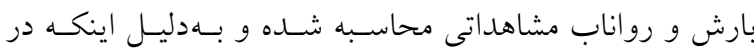

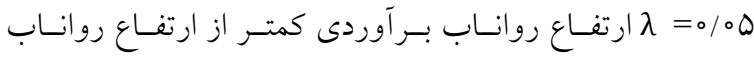

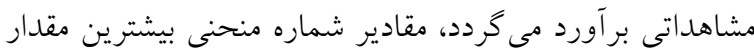

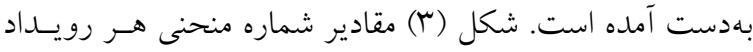

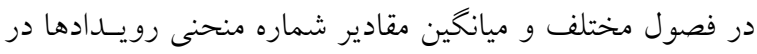

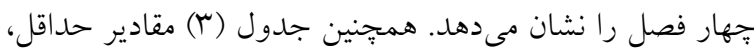

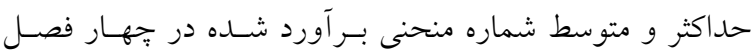
مختلف سال را ارائه مى دهد.

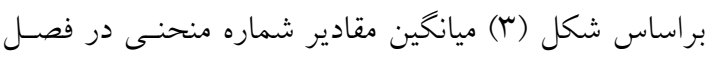
زمستان بيشترين و در فصل بهار كمترين مقدار را دارد. همجنين

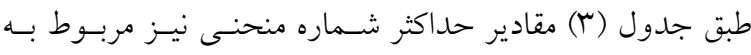

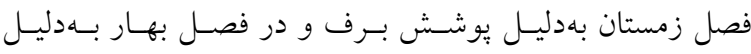
رطوبت بيشين خاك مىباشد. كمترين مقدار شماره منحنى نيـز

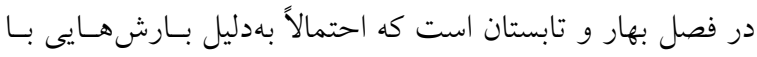

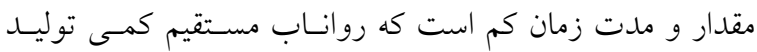
كردهاند. از طرفى فصل بهار و تابستان در منطقـه مـورد مطالعـهـ مصادف با دوره رشد يوشش جنحكلى بـوده و در نتيجـه مقــدار

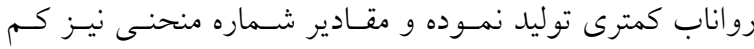

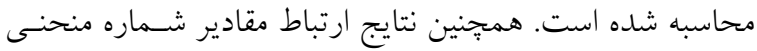
بر آورد شده و خصوصيات بارش و ضريب رواناب بـهـهورت نمودارهاى سه متغيره در شكل هاى (Y) تا (Y) ارائه شده است.

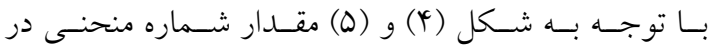
بارش هاى كل بين هr تا مه ميلى متر و مقدار بـارش مسؤثر بـين

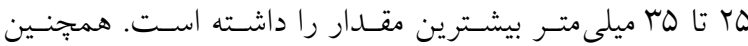
براساس شكل (9) در شدت بارش بالاو مدت كم و يا عكس فس فائ آن در شدت بارش كم و مدت بالا مقدار شماره منحنى به ميزان بيشترى برآورد شده است.
Xرفت. مقادير مورد انتظار براى Z Xماره منحنى) در نقطـه

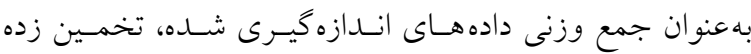

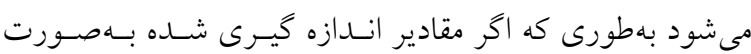
zرنظر كرفته شوند، مقادير تخمينسى بـا استفاده از رابطه (V) قابل محاسبه مىباشد. $\mathrm{Z}^{*}\left(\mathrm{x}_{\mathrm{o}}\right)=\sum_{\mathrm{i}=1}^{\mathrm{n}} \lambda_{\mathrm{i}} \mathrm{z}\left(\mathrm{x}_{\mathrm{i}}\right)$

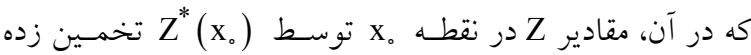

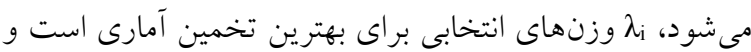

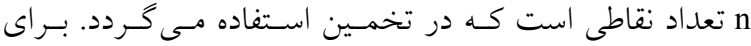
انتخاب روش مناسب درونيـابى جهـت تهيـه نمودارهـاى سـهـ

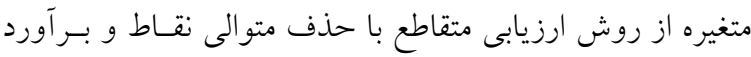
مقادير آن و سعس جايكزينى و برآورد مجدد مقادير حذف شده

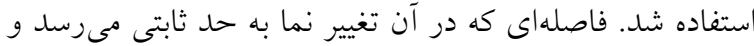

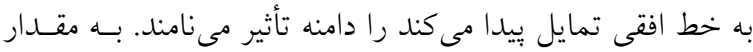
ثابت تغيير نما در دامنه تأثير، سقف يا آستانه اطلاق مى كردد كه الثها

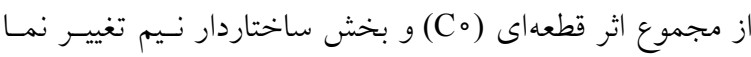

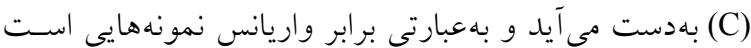

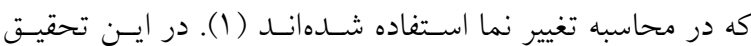

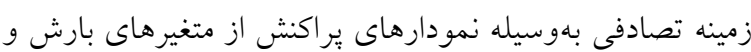
رواناب مشخص مىشود و مقادير بهدست آمده مربوط به مقادير

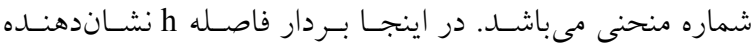

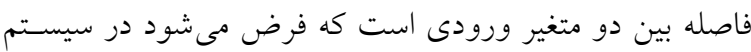

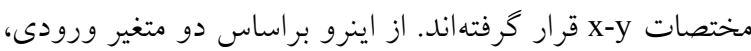
امكان رسم دامنه هاى مختلف تغييرات شماره منحنسى در نقشـهـ

$$
\text { فر اهم مى خردد. }
$$

\section{نتايج}

SCS- مقادير شماره منحنى براى سم رويداد با استفاده از مــل CN

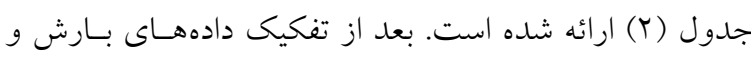
رواناب براساس فصـل، تفـاوت آمـارى ميـان مقــادير شـماره منحنى در فصول مختلف و مقادير متفاوت ل با آزمسون آنـاليز معادير تُعاره 


\begin{tabular}{|c|c|c|c|c|c|c|c|c|c|}
\hline \multicolumn{10}{|c|}{ جدول Y. مقادير شماره منحنى براى بr رويداد در حوضه آبخيز جعفر آباد استان گلستان } \\
\hline$\lambda=0 / \circ \Delta$ & $\lambda=0 / 1$ & $\lambda=0 / 10$ & $\lambda=0 / r$ & رويداد & $\lambda=\circ / \circ \Delta$ & $\lambda=0 / 1$ & $\lambda=0 / 10$ & $\lambda=0 / r$ & رويداد \\
\hline $9 \Delta / \Gamma_{1}$ & $\mu_{0 / 9 \varphi}$ & $49 / 94$ & $\Delta \wedge / v 1$ & מז & VT/Ar & $r q / 4 q$ & $00 / T G$ & $\Delta Q / \Lambda \Lambda$ & 1 \\
\hline $0 / 00$ & $19 / 09$ & $m+/ 9 q$ & $\uparrow \wedge / \Delta Q$ & TY & $\Delta 1 / 40$ & $r V / r q$ & $r q / 0 r$ & $0 \wedge / \circ q$ & r \\
\hline$Q T / V Y$ & $Y \circ / T Y$ & $D G / F Y$ & $99 / 11$ & ro & $\Lambda V / G V$ & $r y / q r$ & $0 \circ / \mu_{1}$ & $90 / 90$ & $r$ \\
\hline $19 / 09$ & $r 1 / 9 T$ & $r \Delta / r_{1}$ & $49 / \pi 1$ & r4 & $V I / T 1$ & $V Q / T Y$ & VN/1。 & $\Lambda \circ / \mu_{0}$ & r \\
\hline$q \circ / \pi \mu$ & $91 / 19$ & $91 / 90$ & $q r / 4 q$ & TV & $V V / T Y$ & & $\varphi \wedge / \circ \varphi$ & $\Delta \Lambda / \circ \Delta$ & 0 \\
\hline$\Lambda r / 01$ & $r \Delta / \Lambda \Lambda$ & $r q / 9 \wedge r$ & $0 \circ / \pi q$ & rᄉ & $\Delta Q / \circ \mu$ & $r 1 / 9 T$ & $|Y| T \mid$ & سM/MT & 9 \\
\hline$\Lambda \circ / \Lambda \varphi$ & $10 / 9 \mu$ & $r q / 40$ & $149 / 09$ & $r q$ & $\% / 00$ & $V / 99$ & $19 / 09$ & $r Q / \circ Y^{C}$ & V \\
\hline $91 / 91$ & IV/AN & $\mu_{0} / \notin v$ & $|q| / 4 \mid$ & ro & $\Lambda r / r q$ & $r 9 / 19$ & $4 \circ / 1 \wedge$ & $\Delta \circ / \Lambda \Lambda$ & $\wedge$ \\
\hline$\wedge 9 / 0^{\circ}$ & $r V / 9 Q$ & $Y r / 9 \circ$ & $\Delta r / \circ q$ & M & $\varphi \circ / \mu \Delta$ & $01 / 79$ & $\Delta \wedge / \uparrow \wedge$ & $94 / 9 \Lambda$ & 9 \\
\hline $11 / \circ \Delta$ & $0 r / 91$ & $99 / 19$ & $V \psi / \circ q$ & rt & $0 \circ / \circ \mu$ & $\Delta \wedge / \Delta 1$ & $s \psi / r_{0}$ & GN/TV & 10 \\
\hline$\circ / 00$ & $r \circ / 11$ & $r \Delta / r \Delta$ & $Y \wedge / T 1$ & سץ & $q r / r q$ & 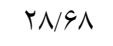 & $F Y / M$ & $\Delta \Delta / 9 \circ$ & 11 \\
\hline$V Q / \circ \Lambda$ & $\Lambda r / \Lambda 。$ & $\Lambda \mathrm{V} / \mathrm{AV}$ & $\Lambda \uparrow / \mathcal{F} \wedge$ & ry & $G D / T^{N}$ & $r M / 9 V$ & $r \Delta / v q$ & $\forall \Delta /{ }^{\prime} \wedge$ & Ir \\
\hline $01 / A \Lambda$ & TS/VD & rN/4G & $F V / 4 Y$ & ro & $V Y / 9 \Lambda$ & $D 1 / 4 T$ & $G 4 / 1 V$ & $V 1 / 9 V$ & 11 \\
\hline$\Lambda \circ / \Upsilon \Lambda$ & $\mu r / 00$ & $\Delta V / T V$ & $99 / 94$ & re & 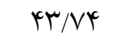 & $\Delta Y / 1 \circ$ & $90 / 199$ & $90 / \mathrm{VV}$ & 14 \\
\hline $91 / 90$ & $\Delta \Delta / V Y$ & $99 / 19$ & VV/AG & rv & $4 \circ / 90$ & $49 / 91$ & $09 / T G$ & $90 / 9 V$ & 10 \\
\hline$Q T / T 4$ & $0 . / 49$ & $9 \Delta / V \wedge$ & $V Y / V \Delta$ & ऍ人 & $19 / \uparrow q$ & $94 / 0 \circ$ & $V G / T Q$ & $\Lambda T / \Delta D$ & 19 \\
\hline$\Lambda T / \Delta Q$ & Tr/gYq & $\forall \wedge / T^{\mu}$ & $\Delta \wedge / 9 V$ & rq & $9 \Delta / \wedge \Delta$ & rT/VA & $49 / 00$ & $\Delta \Delta / \uparrow \wedge$ & IV \\
\hline$\varphi \circ / \mu q$ & $01 / 4 Y$ & $0 / / 9 q$ & $9 \mu / 90$ & $\varphi_{0}$ & $94 / 01$ & TY/OH & rq/oq & $01 / T V$ & 11 \\
\hline $0 / 00$ & $10 / 0 Y$ & $19 / 0 \mathrm{~V}$ & $r Q / D V$ & 41 & $90 / 91$ & TV/GV & $\Delta Y / 91$ & $90 / 10$ & 19 \\
\hline $0 \circ / 1 \wedge$ & $90 / r^{4}$ & VT/KT & $V Y / T I$ & kr & $9 \Delta / 4 \wedge$ & $0 \mathrm{H} / 99$ & $9 N / 94$ & $\mathrm{VV} / \Delta Q$ & ro \\
\hline$\Delta V / D G$ & $99 /{ }^{4} \wedge$ & $90 / 11$ & GV/AG & er & $V 9 / 19$ & rN/l。 & $F \mid / V \mu$ & $01 / 94$ & YI \\
\hline - & - & - & - & - & $9 \mathrm{~V} / \circ \Delta$ & $\mathrm{V} / 0 \mathrm{H}$ & $9 V / 99$ & $V Y / 94$ & Tr \\
\hline
\end{tabular}

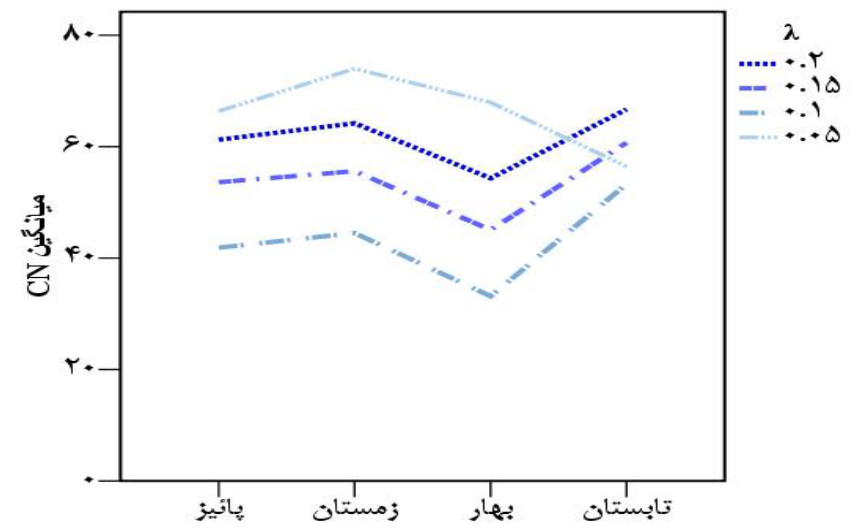

شكل r. ميانگين مقادير شماره منحنى محاسباتى در جهار فصل با مقادير مختلف 


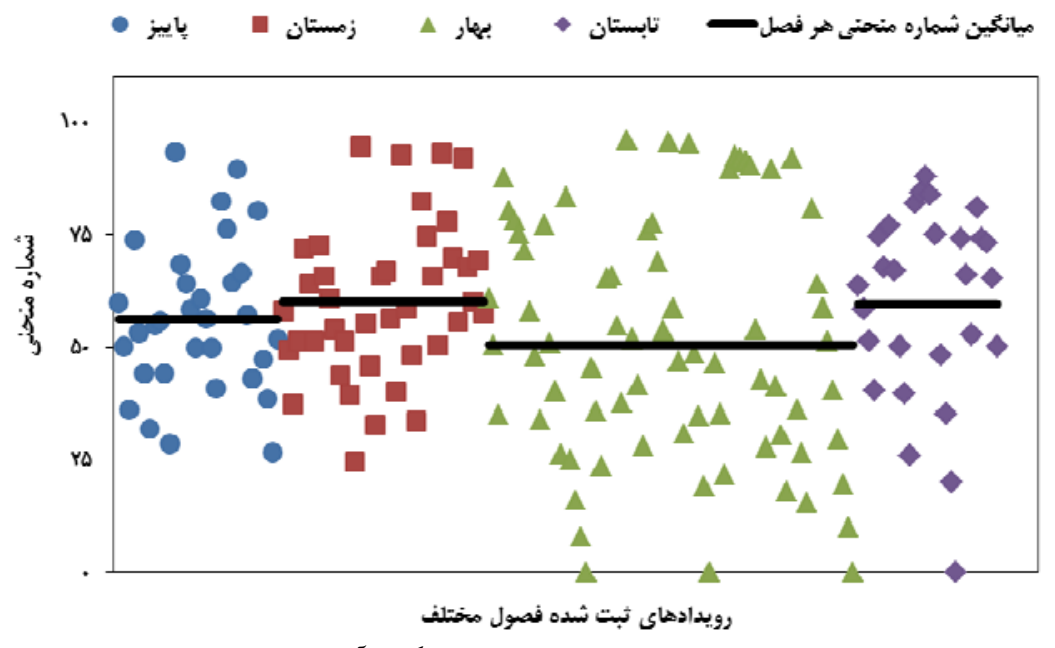

شكل r. مقادير شماره منحنى محاسباتى رويدادهاى ثبت شده و ميانگين آنها در فصول مختلف در دوره مورد مطالعه

جدول r. خصوصيات آمارى مقادير شماره منحنى در فصول مختلف سال

\begin{tabular}{|c|c|c|c|c|}
\hline تابستان & بهار & زمستان & پِاييز & آماره \\
\hline$\Lambda \mathrm{V} / \Lambda \mathrm{V}$ & $90 / 9 \wedge$ & $94 / 01$ & $q 4 / r q$ & حداكثر \\
\hline$\%$ & $\circ / 00$ & TY/OH & TE/VQ & حداقل \\
\hline $09 / 90$ & $0 . / 9 Y$ & $90 / 11$ & $\Delta \& / Y \wedge$ & ميانگين \\
\hline
\end{tabular}

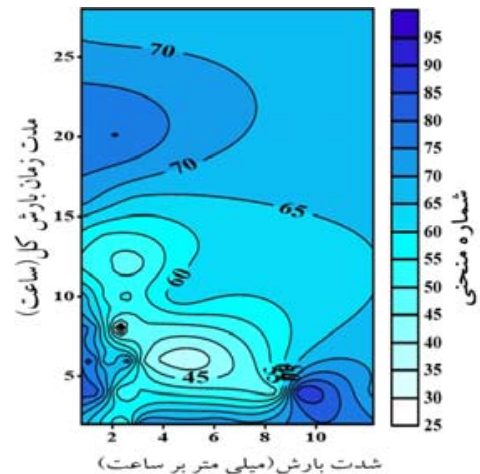

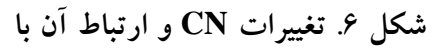

شدت بارش و مدت بارش كل

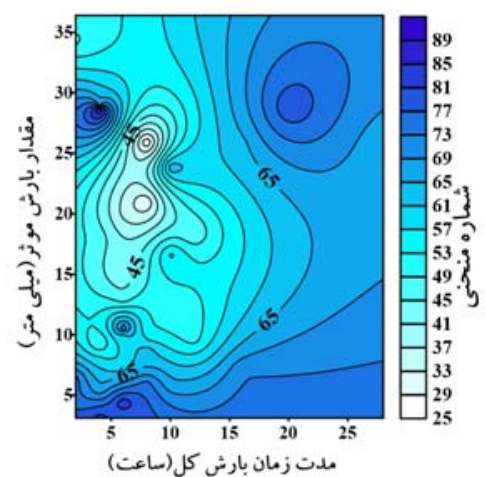

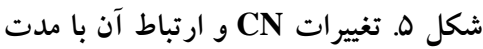
بارش و مقدار بارش مؤثر

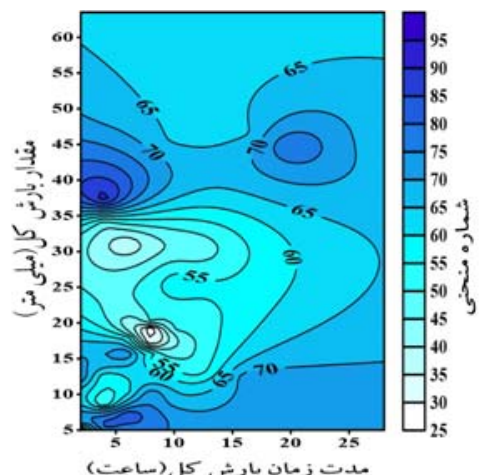

شكل \& ا. تغييرات CN و ارتباط آن با مدت كات بارش كل و مقدار بارش كل

مقدار شماره منحنى با مقدار بارش كل و بارش مـؤثثر براسـاس شده است.

با توجه به نتايج ارائه شده در شكل (ها)، تغييـرات مقـدار

شماره منحنى با ارتفاع رواناب داراى ارتبـاط ضـعيفى اسـت. از طرفى در شكل (11) مشخص است كه مقدار شماره منحنسى در Vo بارش هايى با تداوم To ساعت، دار اى شماره منحنسى بـالاى
شكل (V) داراى ارتباط مستقيم است. در مقادير بالاى بارش كل و بارش مؤثر كه بيشترين نقش را در توليد رواناب داشـتهانــ و مقادير بالاى ضريب رواناب را توليد كردهانـد، براسـاس شـكل ( ) و (9) مقدار شماره منحنى نيز بـه ميـزان بيشـترى محاسـبه 


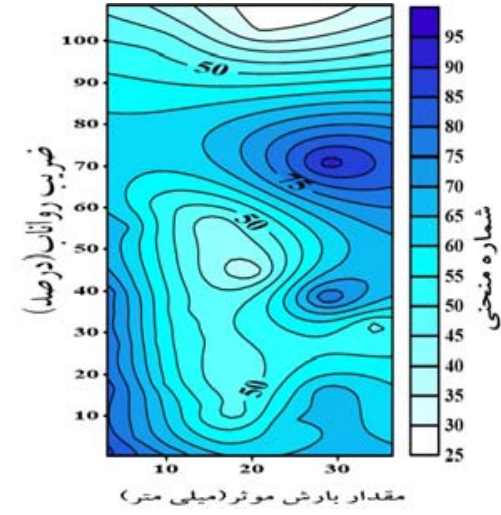

شكل 9.

بارش مؤثر و ضريب رواناب

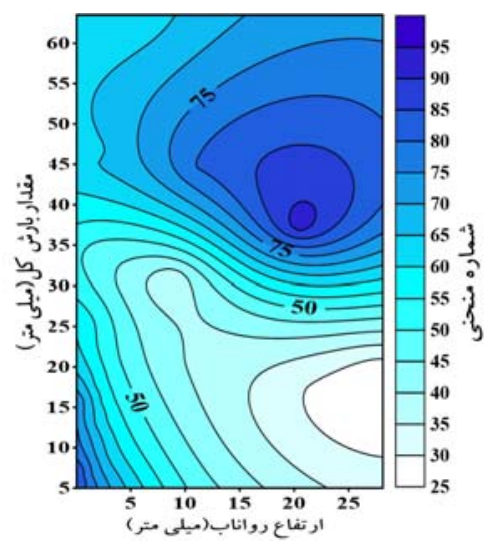

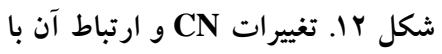

$$
\text { ارتفاع رواناب و مقدار بارش كل }
$$

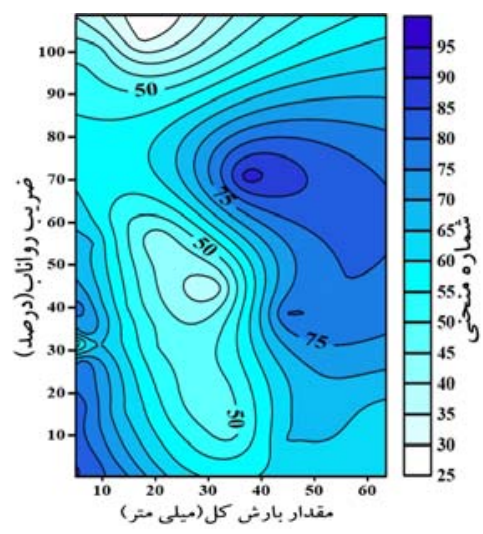

شكل ^^ تغييرات CN و ارتباط آن با مقدار بارش كل و ضريب رواناب

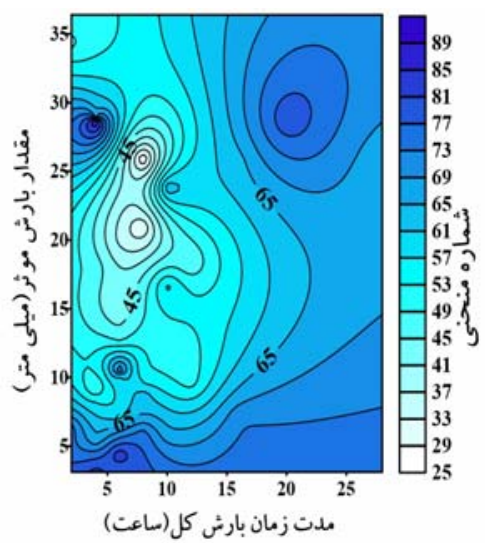

شكل II. تغييرات CN و ارتباط آن بان بات

$$
\text { ارتفاع رواناب و مدت بارش كل }
$$

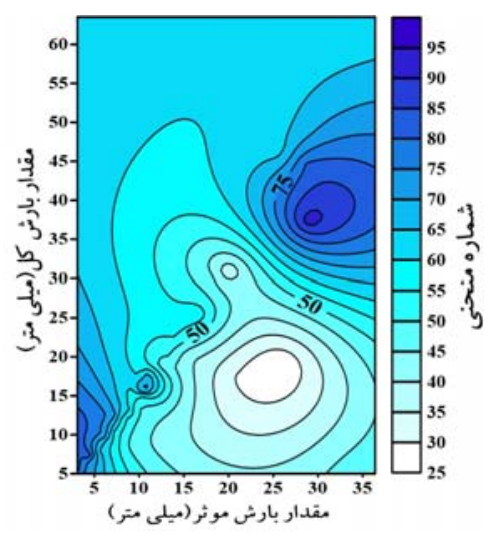

شكل V. تغييرات CN و ارتباط آن با مقدار

بارش مؤثر و مقدار بارش كل

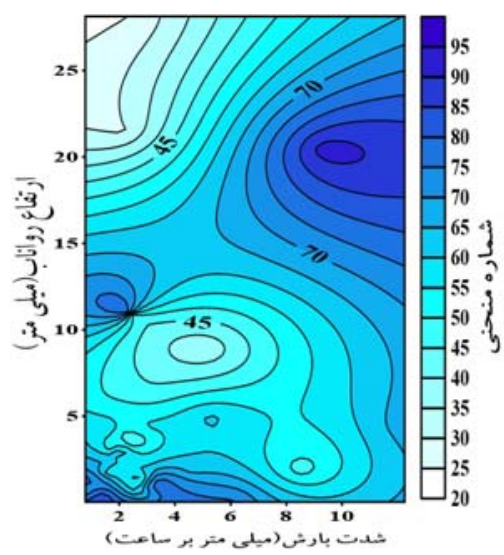

شكل • ا. تغييرات CN و ارتباط آن بات بات

شدت بارش و ارتفاع رواناب
شماره منحنى از روى جداول بدون صسحتسـنجى داراى خطبـ

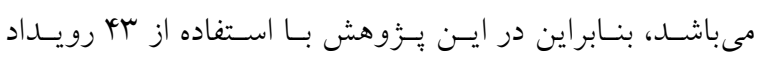

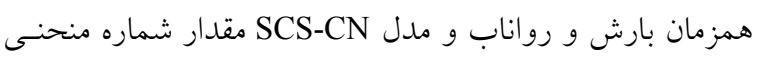

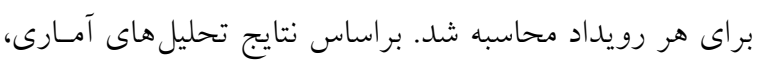
تفاوت معنى دارى ميان مقادير شماره منحنى در فصول مختلـف وجود ندارد و وجود تفاوت در مقادير ميانكين شماره منحنى را

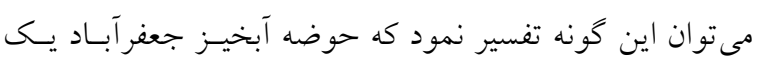

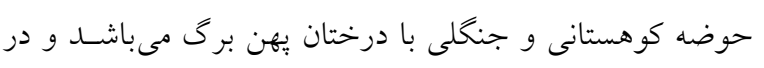

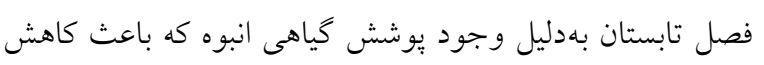
رسيدن بارش به سطح زمين و نفوذ در خاى مى شود و در فصل
مىباشد. همجنين تغييرات شماره منحنى در شكل (Y I) ارتبـاط بيشترى با تغييرات مقدار بارش نسبت به ارتفـاع روانـاب دارد. در مجموع، در رويدادهايى با مدت و مقدار بـارش بـالا مقـدار شماره منحنى نيز بالا بر آورد شده است.

$$
\text { بحث و نتيجه كيرى }
$$

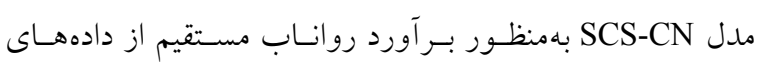

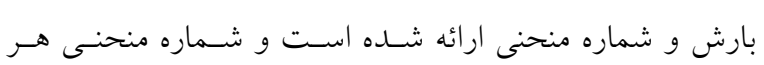
حوضه نشانكر رفتار هيدرولوزيكى و رزيم آب دهى آنى آن حوضسه

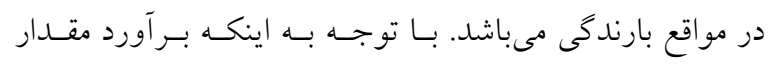


منحنى بالاى VQ را نشـان مسىدهنــ شـكل (1) و (9). در ايـن

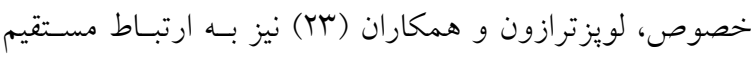

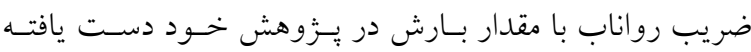

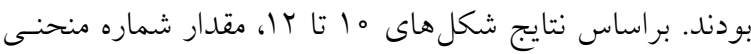

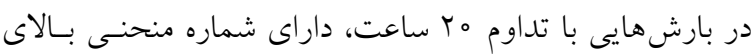

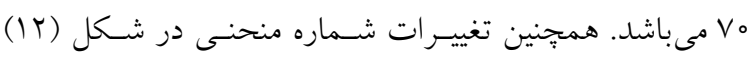

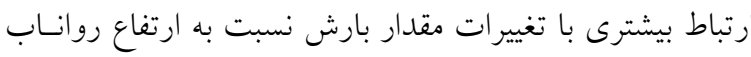

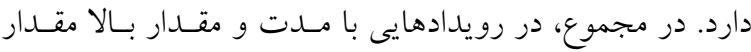

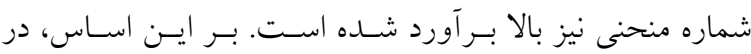

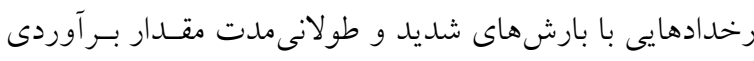

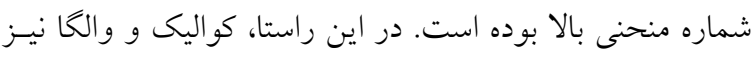
به ارتباط قوى ميان مقادير شـماره منحنسى مشـاهداتى و مقــدار بارش اشاره نمودهاند (YI). براساس نتايج، مقادير بالاى شـماره

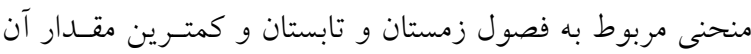
در فصل بهار مىباشد. استفاده از مدلهاى نمـودار سـه متغيـره، امكان ارزيابى همزمان عوامل مؤثر بر تغييرات شماره منحنسى و

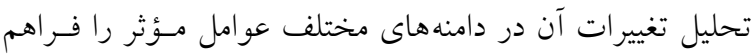
نموده است. با بررسى نمودارهاى سـه متغيـره مسىتـوان نتيجـه

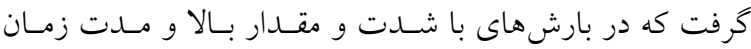

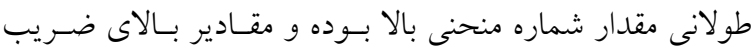
رواناب نشاندهنده مقدار بالاى شماره منحنى مى باشد. براساس

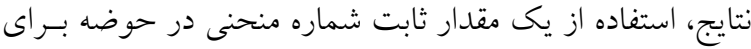

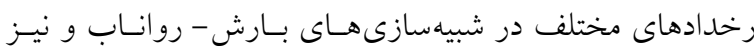
بــرآورد روانـاب در فصـول مختلـف، بايســ براسـاس تحليـل خصوصيات بارش و رواناب در حوضههاى مشـابه و يـا داراى

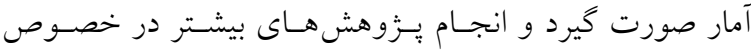
لحاظ ويزّكىهاى بارش در برآورد شماره منحنى از بيشنهادهاى

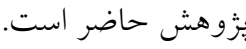

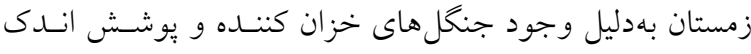

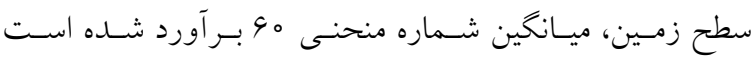

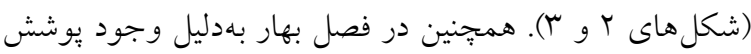

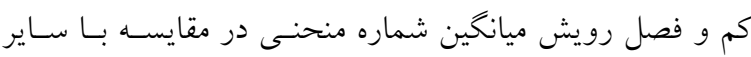

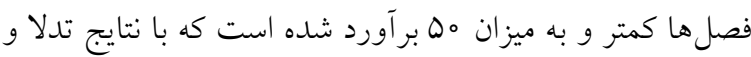

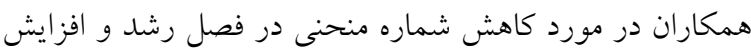

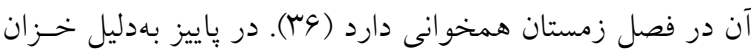

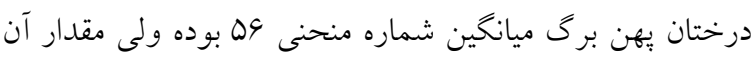

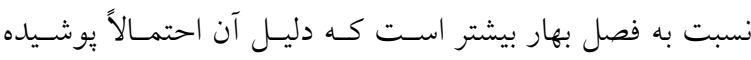

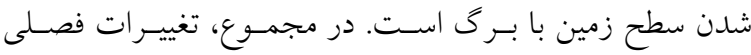

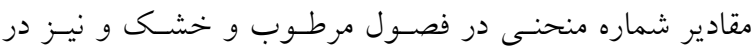
دورههاى مختلف رشد يوشش گياهى در تحقيقات متعدد تدلا و

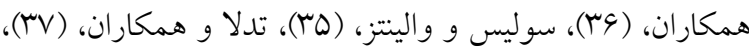

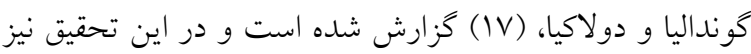
اين تغييرات در فصل هاى مختلف مورد تائيســ قـرار كرفـت. در

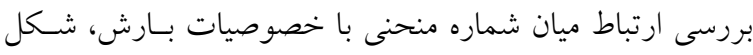

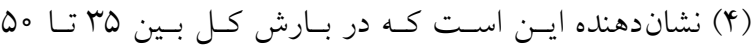
ميلى متر در تمام مدت بارشهاى ثبت شده مقدار شماره منحنى

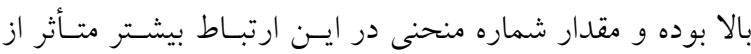

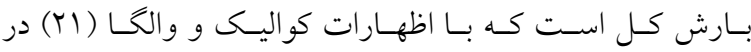

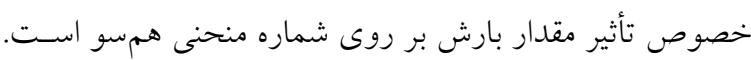
همجنين، نتيجه مشابهى در خصوص ارتباط بين بـارش مـؤثر و

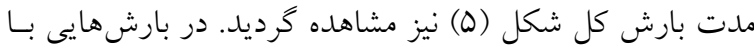
شدت بالا در مدت زمان كم و يا شدت بـايين و مــدت بـارش طولانى تر شكل (9)، مقدار شماره منحنى بيشتر از 90 بـوده كـهـ

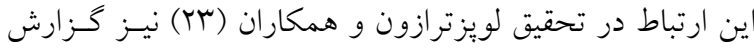
شده است. در رخدادهايى كه مه-ه ثا درصد مقدار بـارش آنها به عنوان رواناب مستقيم از حوضه خارج شدهاند مقـادير شـماره

\section{منابع مورد استفاده}

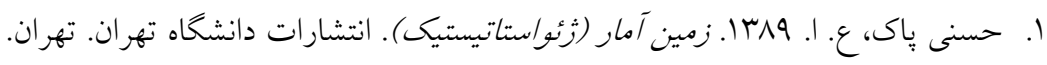
r. عزيزيان، ا.، وع، شكوهى. سجوبا. توسعه روشى براى تخمين شماره منحنى حوضه با استفاده از مفهوم مازاد اشباع (مطالعه موردى: 


$$
\begin{aligned}
& \text { حوضه آبريز كسيليان). تحقيقات منابع آب ايران س( (1): } \\
& \text { س. قهرودى تالى، م. هربا. ارزيابى مدل SCS-CN در تخمين رواناب (مطالعه موردى: حوضه آبريز سد امير كبيـر كـرج). جغرافيـا و } \\
& \text { توسعه. } 11 \Lambda 0-19 \Lambda:(V) Y \\
& \text { צ. محمدى مطلق، ر.، ن. جلال كمالى و ا. جالال كمالى. سوبا. ارزيابى رابطه SCS در تعيـين تلفـات اوليـه بـاران در حوضـه آبريـز } \\
& \text { دالكى. علوم و فنون كشاورزى و منابع طبيعى، علوم آب و خاى لو } \\
& \text { ه. مصطفىز اده، ر.، ا. سعدالدين، ع. ر. بهرهمند، ب. شيخ و ح، نظرنزاد. 9^ها. ارزيابى اثرات هيدرولوزيك طرح آبخيزدارى جعفر آباد }
\end{aligned}
$$

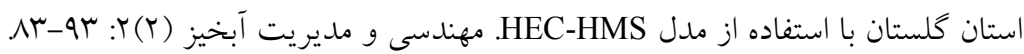

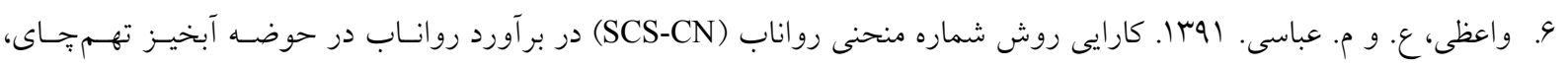

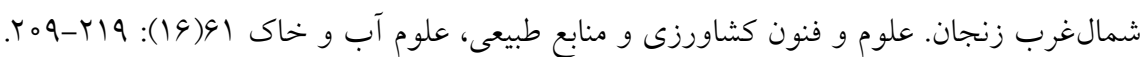

7. Agirre, U., M. Goni, J. J. Lopez and F. N. Gimena. 2005. Application of a unit hydrograph based on sub-watershed division and comparison with Nash's instantaneous unit hydrograph. Catena. 64: 321-332.

8. Ahmad, I., V. Verma and M. K. Verma. 2015. Application of curve number method for estimation of runoff potential GIS environment. $2^{\text {nd }}$ ICGCE 80:16-20, 10-11 January, United Arab Emirates.

9. Altunkaynak, A., M. Özger and Z. Sen. 2003. Triple diagram model of level fluctuation in Lake Van, Turkey. Hydrol. Earth. Syst. Sci. 7(2): 235-244.

10. Altunkaynak, A., and K, Wang. 2010. Triple diagram models for prediction of suspended solid concentration in Lake Okeechobee, Florida. J. Hydrol. 387: 165-175.

11. Bahremand, A and R. Mostafazadeh. 2010. Comparison of different methods for parameter estimation of Nash's instantaneous unit hydrograph in JafarAbad watershed. Watershed Mgmt. Res. J. 86: 42-51.

12. Banasik, K., A. Krajewski., A. Sikorska and L. Hejduk. 2014a. Curve number estimation for a small urban catchment from recorded rainfall-runoff events. J. Environ. Prot. 40(3): 75-86 .

13. Banasik, K., A. Rutkowska and S. Kohnova. 2014b. Retention and curve number variability in a small agricultural catchment: the probabilistic approach. Water. 6: 1118-1133 .

14. Beasley, D. B., L. F. Huggins and E. J. Monke. 1980. ANSWERS: A model for watershed planning. Transactions of the ASAE. 23(4): 938-944 .

15. Blume, T., E. Zehr and A. Bronstert. 2007. Rainfall-runoff response, event-based runoff coefficients and hydrograph separation. Hydrolog. Sci. J. (52)5: 843-862 .

16. Chatterjee, C., R. Jha., A. K. Lohani., R. Kumar and R. Singh. 2002. Estimation of SCS curve number for a basin using rainfall-runoff data. J. Hydraul. Eng. 8(1): 40-49.

17. Gundalia, M and M. Dholakia. 2014. Impact of monthly curve number on daily runoff estimation for Ozat catchment in India. OJMH. 4: 144-155.

18. Hawkins, R. H. 1993. Asymptotic determination of runoff curve number from data. J. Irrig. Drain. E-ASCE. 119: 334-345.

19. Hjelmfelt, A. T. 1980. Empirical investigation of curve number technique. ASCE. 106 (HY9): 1471-1476.

20. Kilgore, J. L. 1997. Development and evaluation of a GIS-based spatially distributed unit hydrograph model. Master degree Thesis, Biological Systems Engineering. Virginia Polytechnic Institute and State University.

21. Kowalik, T and A. Walega. 2015. Estimation of CN parameter for small agricultural watersheds using asymptotic functions. Water. 7:939-955 .

22. Landau, S and B. S. Everitt. 2003. A Handbook of Statistical Analyses using SPSS. PP. 1- 339. CRC Press LLC, Chapman and Hall .

23. Lopez Tarazon, J. A., R. J. Batalla., D. Vericat and J. C. Balasch. 2010. Rainfall, runoff and sediment transport relation in a mesoscale mountainous catchment: the river Isabena (Ebro basin). Catena. 82: 23-34 .

24. McCuen, R.H. 1998. Hydrologic Analysis and Design. PP. 1-883. Pearson Education, Prentice Hall, Upper Saddle River, New Jersey 07458.

25. Mishra, S. K and V. P. Singh. 1999. Another look at SCS-CN method. J. Hydrol. Eng. 257-264 .

26. Moatamednia, M., A. Nohegar., A. Malekian., K, Karimi Zarchi and A. Tavasoli. 2015. Performance of the different models for curve number estimation (Case study: Bar watershed in Khorasan Razavi province, Iran). Ecopersia. 
تعيين شماره منحنى از رويدادهاى بارش و رواناب و تغييرات آن با مؤلفههاى ...

3(3): 1031-1049 .

27. Mostafazadeh, R., A. Bahremand and M, Zabihi. 2015. Efficiency evaluation of Diskin method in derivation of Instantaneous Unit Hydrograph in Jafar-Abad watershed, Golestan Province. Ecohydrology. 2(2): 141-150.

28. Neitsch, S. L., J. G. Arnold., J. R. Kiniry., J. R. Williams and K. W. King. 2002. Soil and water assessment tool (SWAT): Theoretical documentation, version 2000. Texas Water Resources Institute, College station, PP. 1-506. TX, TWRI Report TR-191.

29. Ozger, M and Z. Sen. 2007. Triple diagram method for the prediction of wave height and period. Ocean. Eng. 34(7): 1060-1068.

30. Ponce, V. M and R. H. Hawkins. 1996. Runoff curve number: has it reached maturity. J. Hydrol. Eng. 11-19 .

31. Raghunath, H. M. 2006. Hydrology: Principles, Analysis and Design. PP. 1-476. New Age International.

32. Sadeghi, S. H. R. and R. Mostafazadeh. 2016. Triple diagram models for changeability evaluation of precipitation and flow discharge for suspended sediment load in different time scales. Env. Earth. Sci. 75 : 843. https://doi.org/10.1007/s12665-016-5621-6

33. Sen, Z. 2008. Wadi Hydrology. PP. 1-347. CRC Press.

34. Simanton, J. R., R. H. Hawkins., M. Mohseni-Saravi and K. G. Renard. 1996. Runoff curve number variation with drainage area, Walnut Gulch, Arizona. ASCE. 39(4): 1391-1394 .

35. Soulis, K. X and J. D. Valiantzas. 2012. SCS-CN parameter determination using rainfall-runoff data in heterogeneous watershed-the two-CN system approach. Hydrol. Earth. Syst. Sci. 16: 1001-1015 .

36. Tedela, N. H., S. C. McCutcheon and T. C. Rasmussen. 2007. Effects of seasonal variation on runoff curve number for selected watersheds of Georgia - preliminary study. GWRC, 27-29 March. Georgia .

37. Tedela, N. H., S. C. McCutcheon., J. L. Campbell., W. T. Swank., M. B. Adams and T. C. Rasmussen. 2012. Curve number for nine mountainous Eastern United States watersheds: seasonal variation and forest cutting. J. of Hydrol. Eng. 17: 1199-1203.

38. U.S.DA. Soil Conservation Service. 1993. National Engineering Handbook, Hydrology (NEH-4), Chapter 4.

39. USDA. Natural Resources Conservation Service. 2004. Estimation of direct runoff from storm rainfall. Part 630 Hydrology. National Engineering Handbook. 79p. Chapter 10.

40. Wanielista, M. P. 1997. Hydrology Water Quantity and Water Quality Control. PP. 1-565. Wiley New York.

41. Xiao, B., Q. H. Wang., J. Fan., F. P. Han and Q. H. Dai. 2011. Application of the SCS-CN model to runoff estimation in a small watershed with high spatial heterogeneity. Pedosphere. 21(6): 738-749. 


\title{
Curve Number Determination using Rainfall and Runoff Data and its Variations with Rainfall Components in a Forested Watershed
}

\author{
R. Mostafazadeh*, SH. Mirzaei and P. Nadiri ${ }^{1}$
}

(Received: May 28-2016 ; Accepted: Nov. 16-2016)

\begin{abstract}
The SCS-CN developed by the USDA Soil Conservation Service is a widely used technique for estimation of direct runoff from rainfall events. The watershed CN represents the hydrological response of watershed as an indicator of watershed potential runoff generation. The aim of this research is determining the $\mathrm{CN}$ from recorded rainfall-runoff events in different seasons and analyzing its relationship with rainfall components in the Jafarabad Watershed, Golestan Province. The CN values of 43 simultaneous storm events were determined using SCS-CN model and the available storm events of each season have been separated and the significant differences of CN values were analyzed using ANOVA method. The Triple Diagram Models provided by Surfer software were used to analyze the relationships of CNs and rainfall components. Results showed that the mean values of $\mathrm{CN}$ were 60 for summer and winter seasons and the $\mathrm{CN}$ values in the spring and autumn seasons were 50 and 65, respectively. The inter-relationships of CN amounts and rainfall characteristic showed that the high values of CNs were related to high rainfall intensities (>10 mm/hr) and rain-storms with total rainfall more than $40 \mathrm{~mm}$. Also the CN values were about $>70$ for the storm events with $40-80 \%$ runoff coefficient values.
\end{abstract}

Keywords: Curve Number, Rainfall characteristics, Runoff coefficient, SCS-CN Method, The Jafarabad Watershed, Triple Diagram Model.

1. Dept. of Range \& Watershed Manage. Faculty of Agric. \& Natural Resour., Mohaghegh Ardabili Univ., Ardabil. Iran.

*: Corresponding Author, Email: raoofmostafazadeh@uma.ac.ir 